\title{
Editorials
}

\section{Self-care strategies for asthma}

\section{INTRODUCTION}

The UK National Review of Asthma Deaths (NRAD)," was a Confidential Enquiry on certificated asthma deaths during the 12 months from February 2012; its brief was to establish the accuracy of the diagnosis, whether asthma was the cause of death, and what lessons could be learned. Over twothirds of the asthma deaths verified by the panellists had major potentially preventable factors. Of particular concern was that $45 \%$ of those who died from asthma ether did not seek or get emergency assistance during the final fatal attack; not surprising being that only $23 \%$ had evidence of being issued with a personal asthma action plan (PAAP).

\section{PERSONAL ASTHMA ACTION PLAN}

A PAAP is provided with the intention of informing a patient about their medication: its purpose, how to use it, how to recognise danger signals of poor disease control, what to do when this occurs, and when and how to obtain medical assistance. As asthma is a potentially fatal leven in so called 'mild cases'), chronic, relapsing disease, an appropriate agreed PAAP should be provided for all patients with asthma and their carers by someone appropriately trained. ${ }^{2,3}$ Despite evidence of beneficial outcome in people provided with PAAPs ${ }_{1}^{4}$ these are not provided by health professionals for all people with asthma, 1.5 and evidence is lacking on both the quality of PAAPs issued as well as the background training and expertise of those providing them for patients. Besides anecdotal evidence, little is known of the extent to which asthma care is delegated to untrained individuals, who may not be providing evidence-based advice. In the NRAD, 46\% of nurses performing reviews on those who subsequently died had no formal training in asthma care and there were a number of examples where those doing reviews failed to recognise that patients were at risk, resulting in potentially preventable deaths. ${ }^{1}$ Currently it seems that asthma reviews (including provision of PAAPs) in the UK are often delegated to untrained healthcare

"Besides anecdotal evidence, little is known of the extent to which asthma care is delegated to untrained individuals, who may not be providing evidence-based advice.

assistants, pharmacists, and nurses. In my view, relatively few patients are provided with PAAPs, and in the UK, probably because of the limited requirements (in essence a 'tick box exercise'] imposed by the Quality and Outcomes Framework (QOF), ${ }^{6}$ even fewer are provided with basic education on asthma and the possible risks associated with it.

Daines et al, in their qualitative UK-based study published in this issue of the BJGP, aimed to explore how patients and carers developed and established recommended self-management strategies for living with asthma, and how clinicians can best support the process. Of note, only one-third of this study group had previously been provided with PAAPs. While this study identified two timepoints where educational intervention could have an impact, for example, at diagnosis and at the time of an attack, the findings providevery depressing confirmation of the way patients 'learn intuitively', and are in fact left to their own devices to try and find a way to live with their disease. The whole idea of guided self-management is based on the underlying premise that someone trained in asthma care provides informed guidance for people with asthma land their families) to understand the disease and how best to keep this under control. The examples in Daines et al's article illustrate how patients learn through personal experiences and habits how to recognise danger signs of impending attacks, and how they perpetuate habits learned either personally or experienced through medical management of their disease.

\section{ASTHMA IS NOT AN ACUTE ILLNESS}

Health professional's management as a role model for patients may be beneficial, where the quality of this is evidence based. However, where aspects of the management are inappropriate, patients learn bad habits. Examples include, first, where asthma is treated as if it's an 'acute illness', and patients are sent home after management of exacerbations without identifying or modifying risk factors, or any change in chronic treatment or planned follow-up.' Second, where doctors adopt non-evidencebased practice, such as discharging children from hospital after an asthma attack with unlicensed, extremely high doses of shortacting reliever medication. ${ }^{8}$ Patients adopt the same strategies, from their treatment experiences in general practices or hospitals, for personal self-management behaviour without seeking timely medical advice, or realising that an asthma attack is a signal that their previous treatment has failed and that optimisation of treatment may be needed.

It is interesting to note how Daines et al's' subjects learned and coped with their disease; however, it would also be of great interest to know more about the clinical care and education provided by the subjects' clinicians in order to fully understand the influences on their habits and the intuitive behaviours they developed. This would help in making recommendations for improving self-management, learning, and behaviour. It would also be interesting to know more about how the subjects' aptitude and ability or desire to learn was matched with any instructions they were given by healthcare professionals, in terms of the types of interventions they received and the quality of their expertise and previous training. Were they taught about the nature of asthma? Or that it is an ongoing 'chronic' disease prone to relapses and poor outcome, such as hospitalisation and in some cases death? And were they informed of the different types of asthma medication and importance of taking regular preventer medication? ${ }^{2,3}$ One of the interviewees had clearly 


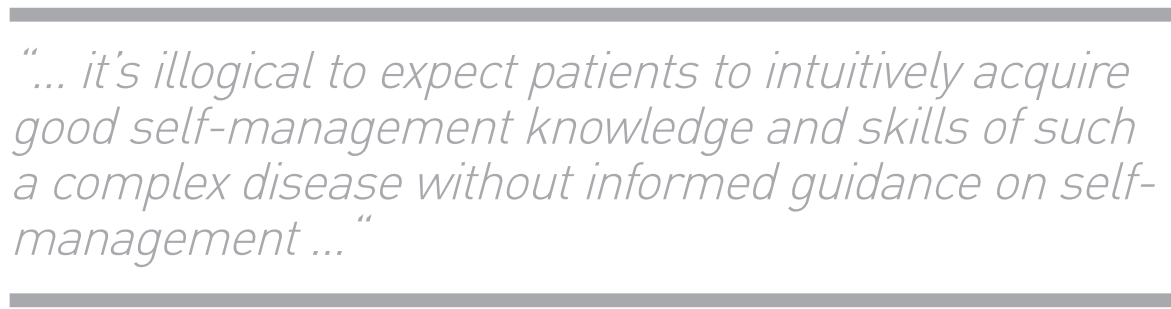

misunderstood the principles of asthma management and stated that I know how far I can push it before I need to stop and take my inhaler ... it's just instinct now'. Sadly, it seems that UK doctors haven't got the message across that over-reliance on reliever medication can be potentially fatal; only one of the 19 recommendations published 6 years ago in the NRAD has been implemented nationally. In my view it's illogical to expect patients to intuitively acquire good self-management knowledge and skills of such a complex disease without informed guidance on self-management; this article by Daines et al, ${ }^{7}$ where a number of subjects had attacks or were using excess relievers, demonstrated inadequate self-management making it difficult to extrapolate any lessons for improving practice. If the experience of these study subjects reflects that of patients in the UK as a whole, it's not surprising that this country ranks so poorly in the world asthma death statistics, 9,10 and has the very high levels of unscheduled asthma care cited in the Daines et al article. ${ }^{7.11}$

\section{MOST ASTHMA ATTACKS AND DEATHS ARE PREVENTABLE}

As most asthma attacks and deaths are potentially preventable, asthma management, and in particular good quality education on self-management, is urgently needed as long as it is provided by appropriately trained individuals. People with asthma should not be left to manage this potentially fatal disease using only their instinctual habits, often guided by poor practice. The key lessons are that those responsible for health care have a duty to discover the way patients are managing their asthma, to identify bad habits and modifiable risk factors, and match appropriate education to these factors. Furthermore, instead of relying on an annual asthma review, clinicians should take opportunities when initially diagnosing and when following patients up after attacks to ensure clear safety-netting advice is provided to encourage people to collect and take their medication correctly, and know how to recognise and act on danger signs. Finally, it is clear that people with asthma should be managed by appropriately trained, knowledgeable healthcare professionals, perhaps supported by trained asthma educators.

\section{Mark L Levy,}

Locum GP, London, UK.

\section{Provenance}

Commissioned; externally peer reviewed.

\section{Competing interests}

Mark L Levy reports personal fees from Clement Clarke International, Teva, Astra Zeneca, Chiesi, Soar Beyond, Orion Pharmaceuticals, National Services for Health Improvement, Novartis Pharmaceuticals, Glaxo Smith Klein, and Trudel Pharmaceuticals. Mark L Levy has also received non-financial support and other from GINA, Napp Pharmaceuticals, and Asthma and COPD (Joint) Lead for Whole Systems Integrated Care North West London; and grants from Consorcio Ricerca in Futura, all outside of the submitted work. Mark L Levy was Clinical Lead for the National Review of Asthma Deaths from 2011-2014.

DOI: https://doi.org/10.3399/bjgp20X709469

\section{ADDRESS FOR CORRESPONDENCE}

Mark L Levy

Email: marklevy@animalswild.com

\section{REFERENCES}

1. Royal College of Physicians. Why asthma still kills: the National Review of Asthma Deaths (NRAD) Confidential Enquiry report. 2014. http://unw.rcplondon.ac.uk/sites/default/files/ why-asthma-still-kills-full-report.pdf laccessed $27 \mathrm{Mar} 2020)$.

2. Global Initiative for Asthma. Global Strategy for Asthma Management and Prevention. 2019. https://ginasthma.org/wp-content/ uploads/2019/06/GINA-2019-main-reportJune-2019-wms.pdf (accessed 27 Mar 2020).

3. British Thoracic Society, Scottish Intercollegiate Guideline Network (SIGN). SIGN 158 British guideline on the management of asthma: a national clinical guideline. 2019. https://mmw. sign.ac.uk/assets/sign158.pdf laccessed $27 \mathrm{Mar}$ 2020).

4. Pinnock H, Parke HL, Panagioti M, et al. PRISMS and RECURSIVE groups. Systematic meta-review of supported self-management for asthma: a healthcare perspective. BMC Med 2017; 15(1): 64

5. Ley ML, Garnett F, Kuku A, et al. A review of asthma care in 50 general practices in Bedfordshire, United Kingdom. NPJ Prim Care Respir Med 2018; 28(1): 29 .

6. NHS Digital. Quality and Outcomes Framework (QOF) business rules v42 2019-2020 baseline release. 2019. https://digital.nhs.uk/data-andinformation/data-collections-and-data-sets/ data-collections/quality-and-outcomesframework-qof/quality-and-outcomeframework-qof-business-rules/quality-andoutcomes-framework-qof-business-rules-v422019-2020-baseline-release laccessed $27 \mathrm{Mar}$ 2020).

7. Daines L, Morrow S, Wiener-Ogilvie S, et al. Understanding how patients establish strategies for living with asthma: a qualitative study in UK primary care as part of IMP2ART. Br J Gen Pract 2020; DOI: https://doi.org/10.3399/ bjgp20X708869.

8. Levy ML, Bush A, Fleming L, et al. Rapid response. Re: Conflicting asthma guidelines cause confusion in primary care. 2018. https:// www.bmj.com/content/360/bmj.k29/rr-8 laccessed 27 Mar 2020).

9. Global Asthma Network. The Global Asthma Report 2018. 2018. http://www. globalasthmareport.org laccessed $27 \mathrm{Mar}$ 2020).

10. Shah R, Hagell A, Cheung R. International comparisons of health and wellbeing in adolescence and early adulthood. 2019 https://mww.nuffieldtrust.org.uk/files/201902/1550657729_nt-ayph-adolescent-healthreport-web.pdf (accessed 27 Mar 2020).

11. Mukherjee M, Stoddart A, Gupta RP, et al. The epidemiology, healthcare and societal burden and costs of asthma in the UK and its member nations: analyses of standalone and linked national databases. BMC Med 2016; 14(1): 113. 